Research article

\title{
Challenges on the conservation of traditional orchards: Tree damage as an indicator of sustainable grazing
}

\author{
Aida López-Sánchez ${ }^{\mathrm{a}, *}$, Ramón Perea ${ }^{\mathrm{a}}$, Sonia Roig ${ }^{\mathrm{a}}$, Johannes Isselstein ${ }^{\mathrm{b}}$, Anja Schmitz ${ }^{\mathrm{b}}$ \\ ${ }^{a}$ Department of Natural Systems and Resources. Universidad Politécnica de Madrid. Ciudad Universitaria s/n, 28040, Madrid, Spain \\ ${ }^{\mathrm{b}}$ Institute of Grassland Science, Georg-August University Goettingen, Von-Siebold-Str. 8, 37075, Goettingen, Germany
}

\section{A R T I C L E I N F O}

\section{Keywords:}

Agroforestry

Trunk debarking

Crown damage

Streuobstwiesen

Individual tree-protection

Animal grazing

\begin{abstract}
A B S T R A C T
Traditional orchard meadows are among the most valuable cultural and agricultural systems for nature conservation in Europe. They comprise scattered fruit trees over a highly diverse herbaceous layer and provide a wide range of ecosystem services. However, they are strongly endangered due to farmland intensification and abandonment. Livestock grazing is known to promote grassland diversity but it may also cause tree damage through debarking. In this study, we evaluated the effect of different grazers (cattle, horse and sheep) on fruit trees in 42 traditional orchards of the Rhenish uplands (Germany). Overall, we found that 70\% of the study trees showed debarking damage, although most of them (40\%) were slightly damaged (1-10\% of the trunk debarked). Most debarked trees showed accumulated damage over time, and only $8 \%$ of the study trees were damaged during the last year. The probability of strong debarking ( $>50 \%$ of the trunk damaged) was higher in orchards grazed by cattle and horses than on those grazed by sheep (5.3 and 3.7-fold difference, respectively). Importantly, unsustainable levels of cumulative debarking caused a decay of crown development, which may strongly affect fruit production. Additionally, lower tree densities favored higher levels of debarking intensity but did not affect the probability of occurrence. Individual tree-protection was an effective practice in decreasing trunk debarking (95\% reduction in tree damage occurrence). The impact of grazing animals on trees might represent a useful indicator to assess the sustainability of each grazing system and should be taken into account in future agriculture and conservation policies.
\end{abstract}

\section{Introduction}

Agricultural landscapes and, particularly, traditional orchards are considered valuable cultural systems (Gibbons et al., 2008; Manning et al., 2006). Orchards represent highly diverse systems with scattered trees growing on grassland vegetation (Lucke et al., 1992). The presence of scattered trees over a grassland matrix is known to promote niche differentiation, favoring higher levels of biodiversity (Garbarino and Bergmeier, 2014; Manning et al., 2006). Scattered trees are also valued by their provisioning, regulating and cultural ecosystem services such as carbon sequestration, fruit and forage production, recreational purposes or their overall aesthetic qualities (Fischer et al., 2010; López-Sánchez et al., 2016; Moreno et al., 2014; Plieninger et al., 2015a).

Traditionally, orchards were important for rural subsistence since they provide fruit for farmers and the local market (Luick and Vonhoff, 2009; Plieninger et al., 2015b). Grazing is practised in some traditional orchards, where extensive livestock farming provides important environmental or economic benefits (Lucke et al., 1992; Pantera et al., 2018). However, nowadays, traditional orchards (as other agroforestry systems) are endangered due to a range of socioeconomic drivers: industrialization of agriculture, reduced economic profitability, increasing opportunity costs, labor-intense management, urbanization and rural abandonment (Garbarino and Bergmeier, 2014; Herzog, 1998; Horak et al., 2013; Nerlich et al., 2013; Weller, 2006). As a result, these systems have significantly declined over the last decades (Eichhorn et al., 2006; Plieninger, 2012) and have lost about $50 \%$ of expanse over 1960-2000 in Europe (ESTO PROJECT, 2014). Beyond the loss of this valuable habitat per se, decline in scattered tree systems may endanger associated plant and animal species created by the tree (Bartolome and McClaran, 1992; López-Sánchez et al., 2016; Ludwig et al., 2004; Rolo et al., 2015). Consequently, in 2007, traditional orchards were designated as a Priority Habitat under the UK Biodiversity Action Plan -BAP-

\footnotetext{
* Corresponding author. Departamento de Sistemas y Recursos Naturales. Universidad Politécnica de Madrid, Ciudad Universitaria, s/n 28040, Madrid, Spain.

E-mail addresses: aida.lopez@upm.es (A. López-Sánchez), ramon.perea@upm.es (R. Perea), sonia.roig@upm.es (S. Roig), jissels@gwdg.de (J. Isselstein), anja. schmitz@agr.uni-goettingen.de (A. Schmitz).
} 
(Robertson and Wedge, 2008) and are currently protected as part of the European Natura 2000 network, the largest ecological network of nature conservation.

Nowadays, remaining orchards are mostly managed to continue a cultural tradition or as a hobby without a strong economic intention (Luick and Vonhoff, 2009). Therefore, the former labor-intensive management practices were pragmatically replaced by labor-extensive grazing management in many cases. However, there is little knowledge on the effect of different grazer species on tree conservation, health and production (Geddes and Kohl, 2009). Moreover, interactions between the grazing animals and the fruit trees, including different management regimes have been little explored. Managers and conservationists are in search of appropriate indicators that can be easily and routinely monitored to assess the sustainability of the system (Dale and Beyeler, 2001). Therefore, further studies should evaluate the impact of grazing animals on fruit trees and assess whether tree damage might become a useful indicator to estimate the ecological sustainability of each grazing management regime.

Livestock can damage trees in different ways. Debarking is considered one of the most common and important types of damage by domestic and wild herbivores, which can eventually cause tree death (Cornelissen et al., 2014; Ihwagi et al., 2010; Mountford and Peterken, 2003). Debarking by large herbivores may cause reduced growth, inappropriate tree development and a decrease in seed/fruit production (Charco et al., 2016; Vasiliauskas, 1998). However, tree debarking and rubbing have been previously studied mostly from a forestry perspective, and particularly for deer and other wild ungulates (Geist, 1998; Kiffner et al., 2008; Perea et al., 2015; Ramos et al., 2006; Velamazán et al., 2017). Although, debarking damage by livestock has been repeatedly recorded in many areas (Kinnaird et al., 1979; Klich, 2017; Kuiters et al., 2006; Nicodemo and Porfírio-da-Silva, 2018), there is anecdotal knowledge on the effect of livestock grazing on tree health of grazed orchards. In addition, livestock preferences for certain fruit tree attributes such as tree size, species or location, still represent a crucial research lacuna. Finally, the type and magnitude of herbivore damage might be modulated by tree and animal density (stocking rates). For example, horse grazing has often been argued as unsuitable due to the high risk of tree debarking but at the same time horses are valued for their ability to control encroaching tall swards and increase diversity levels due to their distinct patch grazing effect and selectivity (Loiseau et al., 1989; Rook et al., 2004). Tree density, and its relationship with livestock damage, is particularly relevant for the management and conservation of traditional orchards since it will affect both the ecological and the economic sustainability. However, the influence of tree density on tree damage by different livestock types and management regimes remains largely unknown.

This study compares the effect of different grazer species (cattle, horses and sheep) on fruit tree damage in the highly valuable traditional orchards of Germany, also known as Streuobstwiesen. We hypothesize that (H1) management with cattle or horses causes greater debarking damage (both occurrence and intensity) than sheep. We also predict that (H2) both the grazing intensity and the management legacy (years under the same grazing system) strongly affect tree debarking occurrence and intensity. We also expect that (H3) lower tree density and larger trees are positively associated with greater debarking damage, and (H4) individual tree-protection reduces debarking occurrence. Finally, we predict that (H5) tree crown development and health is negatively correlated with the intensity of debarking irrespective of the management regime. We expect this study will contribute to evaluate the impact of different grazing management regimes on the conservation of traditional orchards and will provide suitable indicators to assess their longterm sustainability.

\section{Material and methods}

\subsection{Study area}

The study was conducted in managed orchards within the Rhenish uplands in Northrhine-Westfalia, Germany $\left(50.87^{\prime} \mathrm{N}, 7.48^{\prime} \mathrm{E}\right.$; Fig. 1). The study area covers approximately $300 \mathrm{~km}^{2}$ and has a relatively low agricultural production potential with a humid temperate climate [1150 mm of annual mean precipitation and $8.7{ }^{\circ} \mathrm{C}$ of annual mean temperature (geobasis.nrw 2015)]. Soils are shallow, loamy acidic cambisols. Nowadays, grasslands in the study region are mostly managed for dairy production and horses. Traditional sheep grazing decreased in the 20th century and today sheep rearing is mostly performed in the framework of nature conservation purposes or as a hobby.

In the study region, traditional grassland management included management of orchards since the middle ages when orchards established as typical elements of the agricultural landscape. The study area comprises traditional orchards known as "Streuobstwiesen" in Germany and are located in the so called "fruit belt" of Northrhine-Westfalia. Their historical purpose was fruit production for rural and urban areas (Jordan, 2011). The "fruit belt" is a result of increasing population in the metropolitan areas in the Rhine valley as well as favorable local climate conditions. Orchards have been strongly promoted in the 18th and 19th and peaked in the early 20th century (Menke and Homeyer, 2009; Nerlich et al., 2013). Even though a large part of the historical orchards has been lost due to abandonment or land use intensification, the study region is still one of the hotspots of traditional orchards in Germany (Menke and Homeyer, 2009). Grassland vegetation of the study region belongs mainly to the Molinio-Arrhenatheretea (Rivas-Martínez et al., 2001) class and is known for its relatively high nature value (Hünig and Benzler, 2017).

\subsection{Sample design and data collection}

We arranged 42 paddocks (orchards) in 14 triplets within the study area (Table 1; Fig. 1). Each triplet has similar ecological conditions (soil, slope, altitude) and grouped three similar neighboring paddocks grazed by cattle, horse and sheep, respectively. All paddocks have been managed the same way at least for the last 5 years (maximum value 64 years). At all paddocks, we established a plot of $1250 \mathrm{~m}^{2}$. We counted all trees that were found within the plot (tree density) and measured the $\mathrm{dbh}$ (diameter at $1.30 \mathrm{~m}$ high) of each tree. We also recorded the tree indentity (at genus level) of each tree. The main tree identities present in the study paddocks were apple (Malus spp.; 65\%), plum (Prunus spp.; 23\%) and pear (Pyrus spp.; 9\%). The 3\% remaining trees were Juglans spp., Sambucus spp., Quercus spp., and Sorbus spp.

Tree debarking was assessed for all tree trunks. Bark damage due to debarking by grazers was assessed as the percentage of area debarked of the trunk surface. At first step this was done irrespective of the time when the debarking event had taken place. Cumulative damage refers to all damage legacy on the trunk. We considered the cumulative damage through time which was categorized according to its intensity. Damage categories followed a 0-5 rank debarking level following Charco et al. (2016): 0 for trunks with no apparent debarking evidence, 0.5 for trunks with punctual debarking evidence $(<1 \%$ of the trunk damaged, hereafter punctual debarking), 1 for trunks with very low debarking evidence (1-10\% of the trunk damaged, hereafter low debarking), 2 for trunks with lightly debarking evidence (11-25\% of the trunk damaged, hereafter medium debarking), 3 for trunks with relative high debarking intensity (26-50\% of the trunk damaged, hereafter high debarking), 4 for trunks with intense debarking intensity $(51-75 \%$ of the trunk damaged, hereafter heavy debarking), and 5 for trunks with maximum debarking intensity $(>75 \%$ of the trunk damaged, hereafter maximum debarking).

In a second step, we also measured presence and absence $(1 / 0)$ of recent debarking (occurred during the last 12 months and easily 


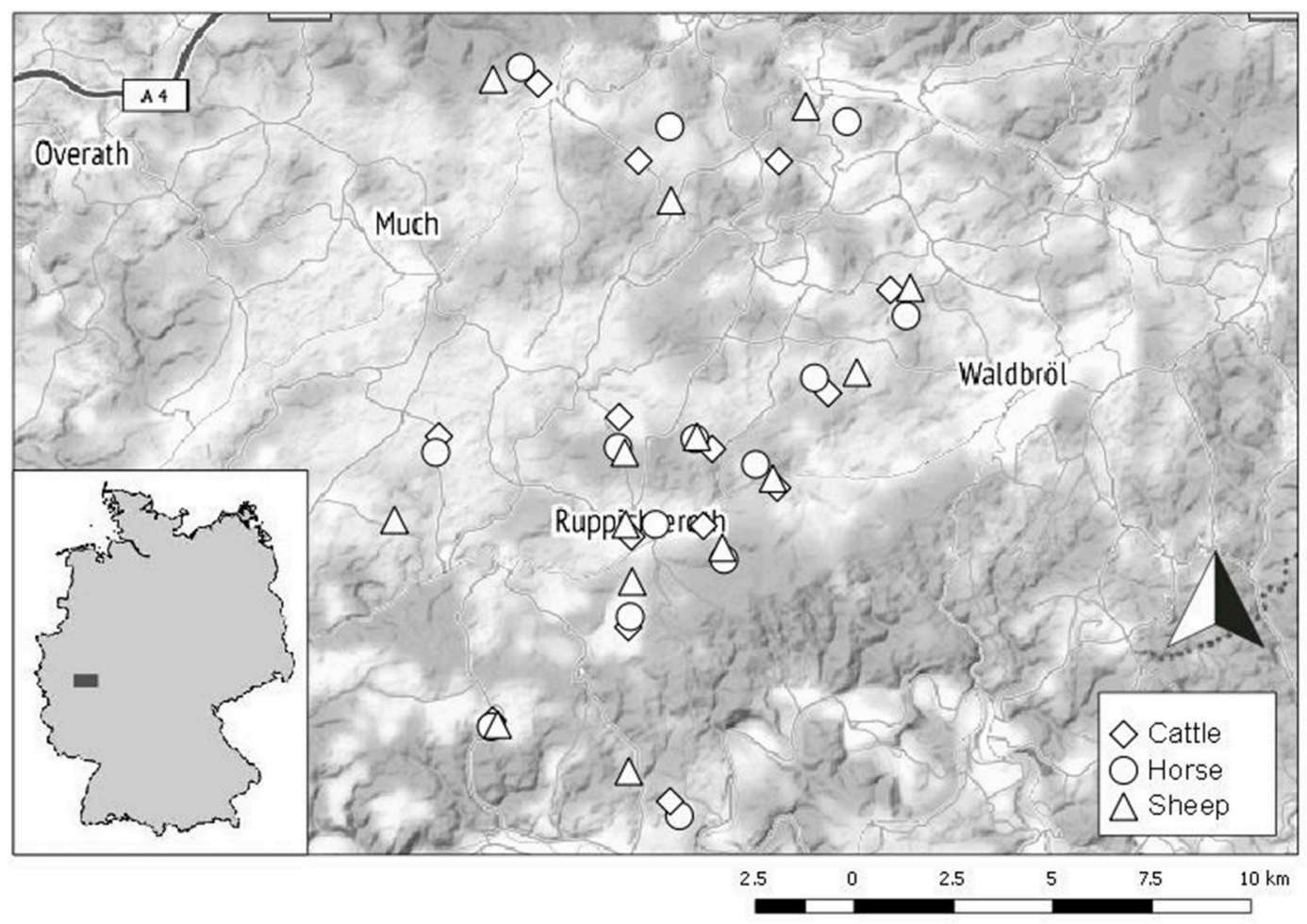

Fig. 1. Location of the 42 paddocks arranged in 14 triplets in Rhenish uplands in Northrhine-Westfalia, Germany. Each paddock comprised three neighboring paddocks of similar ecological conditions grazed by cattle, horse and sheep, respectively.

Table 1

Summary of means \pm sd of the study paddock characteristics.

\begin{tabular}{|c|c|c|c|c|}
\hline Variables & $\begin{array}{l}\text { Cattle } \\
\text { grazing ( } \mathrm{n}= \\
14 \\
\text { paddocks) }\end{array}$ & $\begin{array}{l}\text { Horse } \\
\text { grazing }(\mathrm{n}= \\
14 \\
\text { paddocks) }\end{array}$ & $\begin{array}{l}\text { Sheep } \\
\text { grazing ( } \mathrm{n}= \\
14 \\
\text { paddocks) }\end{array}$ & $\begin{array}{l}\text { Study area } \\
(\mathrm{n}=42 \\
\text { paddocks })\end{array}$ \\
\hline $\begin{array}{l}\text { Grazing } \\
\text { intensity } \\
\text { [LUGD/ha/a] }\end{array}$ & $\begin{array}{l}661.5 \pm \\
427.4\end{array}$ & $\begin{array}{l}627.5 \pm \\
607.5\end{array}$ & $\begin{array}{l}426.2 \pm \\
315.0\end{array}$ & $\begin{array}{l}571.8 \pm \\
466.3\end{array}$ \\
\hline $\begin{array}{l}\text { Management } \\
\text { legacy [years] }\end{array}$ & $34 \pm 20$ & $18 \pm 14$ & $24 \pm 12$ & $25 \pm 17$ \\
\hline Dbh $[\mathrm{cm}]$ & $27.9 \pm 14.8$ & $30.3 \pm 15.7$ & $26.4 \pm 16.2$ & $28.1 \pm 15.6$ \\
\hline $\begin{array}{l}\text { Tree density } \\
\text { [tree number } \\
\text { per plot] }\end{array}$ & $12 \pm 6$ & $10 \pm 4$ & $11 \pm 6$ & $11 \pm 5$ \\
\hline $\begin{array}{l}\text { Tree cover [\% } \\
\text { per plot] }\end{array}$ & $81 \pm 44$ & $44 \pm 23$ & $58 \pm 40$ & $63 \pm 39$ \\
\hline
\end{tabular}

Plot size: $1250 \mathrm{~m}^{2}$.

recognized due to their orange color). To analyze the efficacy of individual tree-protectors in preventing debarking damage we recorded presence and absence $(1 / 0)$ of tree protectors. Individual tree-protectors were established at least 2 years before tree measurements and differed between paddocks according to the preferences of the each paddock's owner. Efficacy of tree protection was only evaluated in relation to recent debarking to avoid historical debarking damage as a confounding factor.

Crown damage was also assessed for all trees and was categorized according to its intensity following the same categories describe for debarking, using defoliation instead of debarking. Tree cover was estimated by digitizing tree crowns (in $\mathrm{m}^{2}$ ) on an aerial photograph (geobasis.nrw, 2012) using ArcGIS 10.3 and related to the ground area of the plot. Information on paddock management was obtained by interviewing the farmers. The management legacy was estimated as the number of years under the same grazer species. Grazing intensity was estimated as live-weight unit grazing days per hectare and year (LUGD ha ${ }^{-1} \mathrm{y}^{-1}$, with
$1 \mathrm{LU}=500 \mathrm{~kg}$, Table 1).

\subsection{Statistical analysis}

In order to analyze trunk debarking as a function of livestock management regime and tree identity, diameter and density, we fitted two maximal models: I) a generalized linear mixed model (GLMMs, Zuur et al., 2009) with occurrence of trunk debarking (presence/absence data) as a response variable; and II) a multinomial log-linear mixed model (Venables and Ripley, 2002) with intensity of trunk debarking as a response variable using trunk debarking categories (see above). Each maximal model included grazer species (cattle, horse and sheep), grazing intensity, management legacy, tree density, tree $\mathrm{dbh}$ and tree indentity (at genus level) as fixed effects. Interactions with biological meaning were also included in the models (see maximal models I and II; Table 2). All analyses included paddock nested within triplet as the random effects structure (Table 2). Occurrence of debarking was fitted to a binomial error distribution with a logit link; and the intensity of debarking was fitted to a multinomial error distribution with a cumulative logit link (Table 2).

For these two maximal models (I and II), we used the model averaging approach (Burnham and Anderson, 2002). We performed model comparison of all possible models by using AIC weights. For that, we used the "dredge" function in the "MuMIn" package of R. Then, models with the best AIC were selected (hereafter top models). Top models were those that had $\triangle \mathrm{AIC}<2$ (Burnham and Anderson, 2002). Finally, we obtained the model-averaged coefficients of top models as well as the relative importance of each predictor (ranging from 0 to 1 ) by using the "model.avg" function of "MuMIn". Residuals were visually checked for heterogeneity in selected top models and the explained deviance as well as the dispersion parameter of each model was calculated to evaluate its fit and ensure no overdispersion (Crawley, 2012).

We also analyzed recent debarking (less than 1 year) as a function of grazer species, grazing intensity and individual tree-protection by fitting another GLMM (model III) with occurrence of trunk recent debarking 
Table 2

Summary of GLMM models performed for data analysis in this study.

\begin{tabular}{|c|c|c|c|c|}
\hline $\begin{array}{l}\text { Maximal } \\
\text { model }\end{array}$ & Response variable & Fixed effect & $\begin{array}{l}\text { Random } \\
\text { effect }\end{array}$ & $\begin{array}{l}\text { Error } \\
\text { distribution } \\
\text { (link function) }\end{array}$ \\
\hline I & $\begin{array}{l}\text { Occurrence of } \\
\text { trunk debarking } \\
{[1 / 0]}\end{array}$ & $\begin{array}{l}\mathrm{GS} \times \mathrm{GI} \times \mathrm{ML} \\
+\mathrm{GS} \times \mathrm{TI}+ \\
\mathrm{TD}+\mathrm{dbh} \times \mathrm{TI}\end{array}$ & $\begin{array}{l}\text { 1|Triplet: } \\
\text { paddock }\end{array}$ & $\begin{array}{l}\text { Binomial (logit } \\
\text { link) }\end{array}$ \\
\hline II & $\begin{array}{l}\text { Intensity of trunk } \\
\text { debarking } \\
\text { [categories of } \\
\text { trunk debarking] }\end{array}$ & $\begin{array}{l}\mathrm{GS} \times \mathrm{GI} \times \mathrm{ML} \\
+\mathrm{GS} \times \mathrm{TI}+ \\
\mathrm{TD}+\mathrm{dbh} \times \mathrm{TI}\end{array}$ & $\begin{array}{l}\text { 1|Triplet: } \\
\text { paddock }\end{array}$ & $\begin{array}{l}\text { Multinomial } \\
\text { (cumulative } \\
\text { logit link) }\end{array}$ \\
\hline III & $\begin{array}{l}\text { Occurrence of } \\
\text { recent debarking } \\
{[1 / 0]}\end{array}$ & $\begin{array}{l}\text { GS } \times \text { GI }+ \\
\text { Protection }\end{array}$ & $\begin{array}{l}\text { 1|Triplet: } \\
\text { paddock }\end{array}$ & $\begin{array}{l}\text { Binomial (logit } \\
\text { link) }\end{array}$ \\
\hline IV & $\begin{array}{l}\text { Occurrence of } \\
\text { crown damage } \\
{[1 / 0]}\end{array}$ & $\begin{array}{l}\text { Intensity of } \\
\text { debarking }\end{array}$ & $\begin{array}{l}\text { 1|Triplet: } \\
\text { paddock }\end{array}$ & $\begin{array}{l}\text { Binomial (logit } \\
\text { link) }\end{array}$ \\
\hline V & $\begin{array}{l}\text { Intensity of crown } \\
\text { damage } \\
\text { [categories of } \\
\text { crown damage] }\end{array}$ & $\begin{array}{l}\text { Intensity of } \\
\text { debarking }\end{array}$ & $\begin{array}{l}\text { 1|Triplet: } \\
\text { paddock }\end{array}$ & $\begin{array}{l}\text { Multinomial } \\
\text { (cumulative } \\
\text { logit link) }\end{array}$ \\
\hline
\end{tabular}

GS: grazer species (cattle, horse and sheep); GI: grazing intensity estimate as live-weight unit grazing days per ha and year [LUGD ha ${ }^{-1} \mathrm{y}^{-1}$ ]; ML: management legacy [years]; TI: tree identity; TD: tree density [trees per plot]; dbh: diameter at height breast [cm]. Categories of trunk debarking: null (no apparent trunk debarking evidence); punctual debarking ( $<1 \%$ of the trunk damaged); low debarking (1-10\% of the trunk damaged); medium debarking (11-25\% of the trunk damaged), high debarking (26-50\% of the trunk damaged), heavy debarking (51-75\% of the trunk damaged), maximum debarking ( $>75 \%$ of the trunk damaged).

(presence/absence data) as a response variable (Table 2). The maximal model included grazer species (cattle, horse and sheep), grazing intensity and individual tree-protection (presence and absence) and their possible interactions as fixed effects (see maximal model III; Table 2). All analyses included paddock nested within triplet as the random effects structure (Table 2). Occurrence of debarking was fitted to a binomial error distribution with a logit link (Table 2). We also used the model averaging approach describe above (Burnham and Anderson, 2002).

In addition to debarking analyses, occurrence of crown damage (presence/absence data; model IV) was assessed as a response variable (fitted to a binomial error distribution) by means of generalized linear mixed models (GLMMs, Zuur et al., 2009). Intensity of crown damage (model V) was also analyzed using crown damage categories (see above) by means of a multinomial log-linear mixed models (Venables and Ripley, 2002). Both maximal models included intensity of debarking as fixed effect and the same random effect structure as the models described above (maximal models IV and V; Table 2).

Data processing and statistics were performed using $R$ 3.2.4 (R Development Core Team, 2015) with the modules "lme4" (Bates et al., 2015), “car" (Fox and Weisberg, 2011), "MuMIn” (Barton, 2015) and "nnet" (Venables and Ripley, 2002).

\section{Results}

\subsection{Probability and intensity of cumulative debarking}

We found that $70 \%$ of all studied trees $(n=457)$ had cumulative debarking damage. Both probability of debarking occurrence (presence/ absence data) and intensity of debarking (damage quantification through debarking categories) depended on the livestock species (Tables 3 and 4). Model selection (see Table S1 and Table S2) is shown in Supporting Information. In cattle- and horse-grazed orchards, the probability of debarking occurrence was very high (mean probability of 0.72 and 0.70 , respectively) and significantly greater than that of sheepgrazed (0.62) orchards (Table 3; Fig. 2).

Most debarking damage corresponded to low levels of debarking intensity (1-10\% of the trunk damaged) with 0.27 probability across all
Table 3

Summary of the top GLMM models to analyze the probability of debarking occurrence.

\begin{tabular}{lllllll}
\hline Predictors & Importance & Factors & Coeff. & SE & $\begin{array}{l}z- \\
\text { value }\end{array}$ & $P$ \\
& & & & & & \\
\hline Intercept & & & 1.505 & 0.511 & 2.936 & 0.003 \\
Grazer species & 0.61 & Horse & -0.921 & 0.521 & 1.763 & 0.078 \\
& & Sheep & -1.075 & 0.516 & 2.079 & 0.038 \\
Grazing & 0.35 & & -0.017 & 0.178 & 0.093 & 0.926 \\
$\quad$ intensity & & & & & & \\
Management & 0.71 & & -0.582 & 0.384 & 1.515 & 0.130 \\
$\quad$ legacy & & & & & & \\
Tree density & 0.45 & & -0.247 & 0.202 & 1.218 & 0.223 \\
dbh & 1.00 & & 0.812 & 0.140 & 5.769 & $<0.001$ \\
GS $\times$ ML & 0.32 & Horse-T & 0.971 & 0.470 & 2.060 & 0.039 \\
& & Sheep·T & 0.746 & 0.520 & 1.431 & 0.152 \\
\hline
\end{tabular}

Grazer species: cattle, horse and sheep; Grazing intensity: estimate as liveweight unit grazing day per ha and year [LUGD ha ${ }^{-1} \mathrm{y}^{-1}$ ]; Management legacy [years]; Tree density [trees per plot]; dbh: diameter at height breast $[\mathrm{cm}]$. GS $\times$ ML: Interaction between grazer species and management legacy.

Table 4

Summary of the top multinomial log-linear mixed models (Likelihood-ratio $\chi^{2}$ test) to analyze the intensity of general trunk debarking.

\begin{tabular}{lllll}
\hline Variables & Importance & d.f & $L R \chi^{2}$ & $P$ \\
\hline Grazer species & 0.53 & 12 & 20.967 & 0.050 \\
Management legacy & 0.86 & 6 & 11.924 & 0.063 \\
Tree density & 0.52 & 6 & 13.668 & 0.034 \\
dbh & 1.00 & 6 & 56.323 & $<0.001$ \\
GS*L & 0.45 & 12 & 29.111 & 0.004 \\
\hline
\end{tabular}

dbh: diameter at breast height.

GS*L: Interaction between grazer secies and legacy.

livestock species (Fig. 2). Trees on cattle- and horse-grazed orchards showed significantly greater intensity of debarking damage than sheepgrazed orchards (Fig. 2). Overall, 16\% and 11\% of the debarked trees showed heavy or maximum damage at cattle- and horse-grazed orchards, respectively whereas sheep paddocks only had $3 \%$ of their debarked trees with heavy or maximum damage (Fig. 2).

Both, the probability and intensity of debarking were strongly related to the tree diameter -dbh- (Tables 3 and 4). Trees with greater dbh showed higher probability of debarking occurrence (Table 3 ), and this occurred for all levels of debarking intensity $(P<0.05)$. Overall, probability of debarking occurrence did not depend on tree density (Table 3); however, for some levels of debarking intensity - such as low and medium debarking levels $(<25 \%$ of trunk damaged), lower tree densities significantly $(P<0.05)$ increased the probability of debarking occurrence (Table 4).

Finally, both the probability and intensity of debarking also depended on the interaction between livestock species and management legacy (Tables 3 and 4). Paddocks with horse management for long periods ( $>25$ years) showed significantly higher probability of maximum debarking damage than any other grazing management regimes across all grazer species and legacy ( $z$-value $=2.204 ; P=0.028$ ). Grazing intensity showed very little effect (relative importance of 0.35 ) on the occurrence of debarking damage (Table 3). The grazing intensitymanagement legacy interaction was not even present in the top models, indicating a very low importance in the occurrence $(0.08)$ and intensity $(<0.01)$ of tree damage (see Tables S1 and S2 in Supporting Information).

We did not find any significant effect of tree identity on debarking occurrence and intensity. This variable was not present in the top models and had very low importance ( 0.16 and $<0.01$, respectively) in the maximal model (see Tables S1 and S2 in Supporting Information). Their interactions with grazer species and tree diameter also had very low importance $(<0.01$; see Tables S1 and S2 in Supporting Information). 


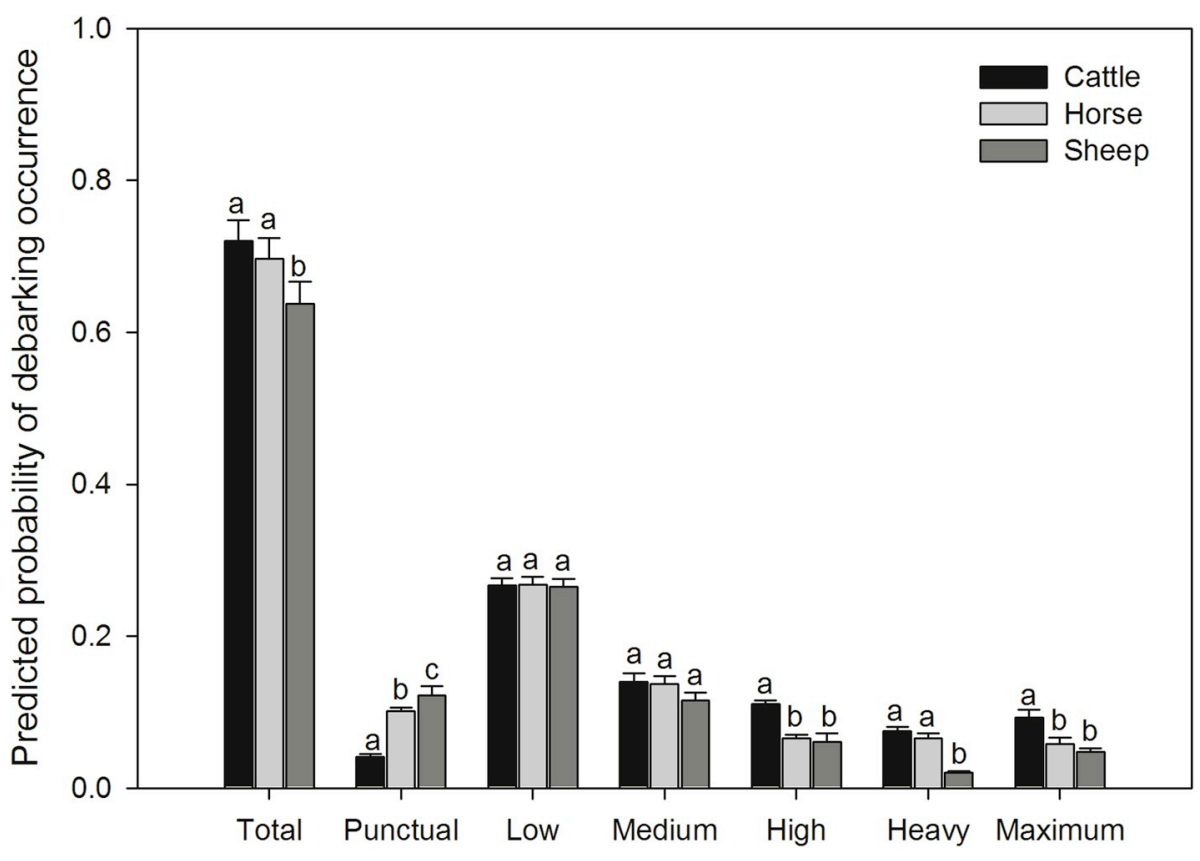

Fig. 2. Predicted probability of debarking occurrence. Predicted probability of a tree being debarked across different damage categories depending on grazer species ( $\mathrm{N}=457$ trees). Error lines are $95 \%$ confidence intervals. Total: presence of damage occurrence; Punctual: $0.5 \%$ of trunk was damaged; Low: $1-10 \%$ of trunk was damaged; Medium: $11-25 \%$ of trunk was damaged; High: $26-50 \%$ of trunk was damaged; Heavy: $51-75 \%$ of trunk was damaged; Maximum: $>75 \%$ of trunk was damaged. Same letters (a, b, c) above bars indicate no significant differences within the same damage category.

The three main genera had similar percentage of debarking occurrence within each genus (72\% for Malus spp., 68\% for Pyrus spp. and 64\% for Prunus spp.).

\subsection{Probability of recent debarking}

In short-term ( $<1$ year), we found very few cases of recent trunk debarking in the study orchards. Only $8 \%$ of the analyzed trees $(n=457)$ showed recent debarking. We did not find differences among grazer species in recent debarking. Grazer species was not even present in the top models, with very low importance (0.29) in the maximal model (see Table S3 in Supporting Information). We did not find a significant effect of grazing intensity in recent debarking (Table 5). Interaction of grazing intensity and grazer species was not even present in the top models due to its low importance (0.03; see Table S3 in Supporting Information). Finally, trees with individual tree-protection showed significantly lower probability of recent debarking occurrence than trees without protection (Table 5). A total of 161 trees had individual tree-protection and only 7 trees experienced recent debarking. Therefore, individual treeprotection was an effective practice in decreasing trunk debarking ( $95 \%$ reduction in tree damage occurrence).

\subsection{Probability and intensity of crown damage}

Debarking had a strong effect on the probability of crown damage occurrence ( $z$-value $=6.137, P<0.001$; Fig. 3$)$ and intensity $\left(\chi_{2}=\right.$ 90.362; $P<0.001$ ). Trunks with higher levels of debarking showed higher probability of crown damage occurrence (Fig. 3) and this

Table 5

Summary of the top GLMM models (deltaAICc $<2$ ) to analyze the probability of recent debarking occurrence.

\begin{tabular}{|c|c|c|c|c|c|c|}
\hline Predictors & Importance & Factors & Coeff. & $S E$ & $\begin{array}{l}z \text { - } \\
\text { value }\end{array}$ & $P$ \\
\hline Intercept & & & -2.451 & 0.278 & 8.797 & $<0.001$ \\
\hline $\begin{array}{l}\text { Grazing } \\
\text { intensity }\end{array}$ & 0.45 & & 0.217 & 0.185 & 1.174 & 0.240 \\
\hline Protection & 0.70 & Yes & -0.823 & 0.452 & 1.815 & 0.049 \\
\hline
\end{tabular}

Grazing intensity: estimate as live-weight unit grazing day per ha and year [LUGD ha ${ }^{-1} \mathrm{y}^{-1}$ ]; Protection: individual protection presence.

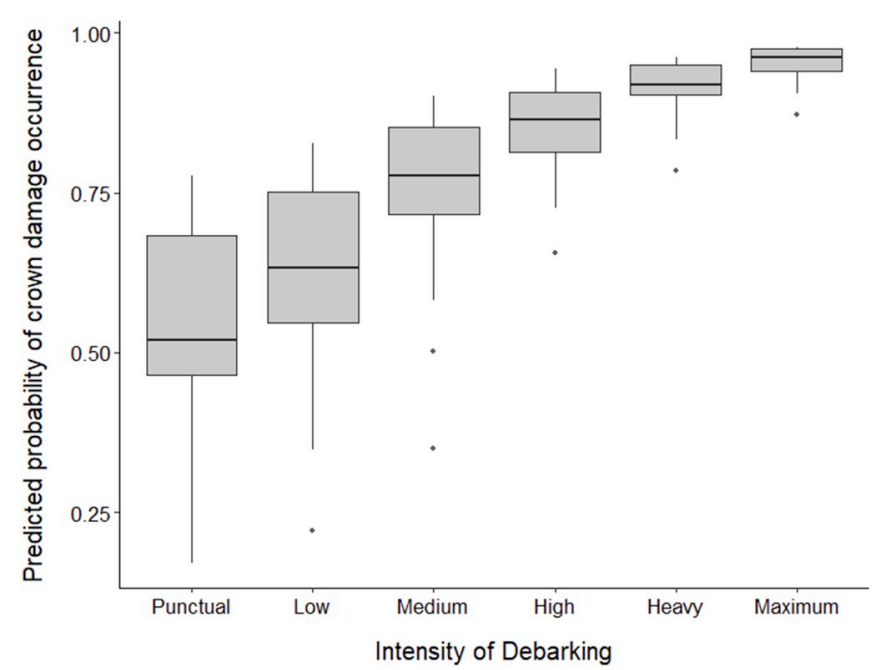

Fig. 3. Predicted probability of crown damage occurrence. Predicted probability of a crown being damaged across different categories of debarking intensity ( $\mathrm{N}=457$ trees). Null: no evidence of debarking; Punctual: $0.5 \%$ of trunk was debarked; Low: $1-10 \%$ of trunk was debarked; Medium: $11-25 \%$ of trunk was debarked; High: $26-50 \%$ of trunk was debarked; Heavy: $51-75 \%$ of trunk was debarked; Maximum: $>75 \%$ of trunk was debarked.

occurred for all levels of crown damage intensity $(P<0.05)$. Thus, trees with heavy and maximum debarking damage showed $>90 \%$ probability of damage on the tree crown (Fig. 3).

\section{Discussion}

\subsection{Impact of grazer species, grazing intensity and management legacy on tree layer}

Our study showed that tree debarking is a common phenomenon in grazed orchards. Grazer species resulted in the second most important variable (after tree diameter) explaining, both occurrence and intensity of cumulative debarking damage. Our results indicate greater probability of damage (0.70) in cattle- and horse-grazed traditional orchards; 
and importantly, some debarked trees ( $16 \%$ for cattle- and $11 \%$ for horse-grazed orchards, respectively) showed significant levels of debarking intensity ( $>50 \%$ of the trunk damaged). Kinnaird et al. (1979) already found several girdled trees after serious debarking by cattle. In contrast, despite the fact that trees in sheep-grazed orchards showed also relative high occurrence of debarking $(0.60)$, the debarking intensity was significantly lower, with very few trees showing high levels of debarking intensity (only $3 \%$ of the debarked trees showed heavy and maximum damage). Nevertheless, overall, the observed orchards do not seem to have very alarming levels of debarking due mostly to their relatively low and not life-threatening damage intensity (Fig. 2). However, heavy and maximum debarking damage represent only $12 \%$ of the total debarking damage but it significantly affected tree crown development (Fig. 3). Therefore, values above $50 \%$ of trunk damage could be considered unsustainable in a long-term basis since significant and repeated damage on the same trees increases tree weakness and may eventually cause their death (Cornelissen et al., 2014; Mountford and Peterken, 2003). Interestingly, we also found a significant effect of management legacy on tree debarking occurrence and intensity. This reinforces the idea that older and larger trees have higher probability of debarking damage due to the continuous impact on the same trees over time. Horse grazing farms, with $>25$ years continuous grazing increased the probability of debarking occurrence and, particularly, the probability of maximum debarking level ( $>75 \%$ of the trunk damaged). This greater debarking impact of horses as compared to cattle can be explained because cattle have no upper incisors and use their tongues as prehensile organs (Walker, 1994) and are not usually able to graze below $12 \mathrm{~mm}$ from the soil (Leigh, 1974). Horses, in contrast, have upper and lower incisors and, thus, are able to graze much closer to the ground than cattle (Rook et al., 2004), which may also explain their greater ability to debark trees. However, very few studies have focused on the origin and extension of tree debarking by horses despite it is well known that they can cause significant damage, particularly on broadleaved trees of forests (Klich, 2017; Kuiters et al., 2006).

Surprisingly, our results also show that livestock did not have any preference for the study tree species, at least within the Rosaceae family. In fact, the three more common genera (Malus spp., Prunus spp. and Pyrus spp) represented $>95 \%$ of all fruiting trees in the study orchards and belonged to the same family (Rosaceae), most likely with minimum inter-specific differences in bark properties.

Finally, stocking rates per se did not show any significant effect on debarking occurrence and intensity. Further studies should address the effect of increasing the stocking rates while controlling for the study predictors (grazer species, tree size and tree density). Other studies have highlighted the importance of animal densities (e.g. deer), particularly on the damage intensity, which usually increases with higher population densities (Iijima and Nagaike, 2015; Kiffner et al., 2008).

\subsection{Effect of tree size and density on debarking impact}

In general, we found that larger trees, with greater diameter (dbh), showed higher probability of having debarking damage. Tree diameter was the most important explanatory variable (relative importance of 1.00 ) in explaining both occurrence and intensity of debarking. Previous studies, however, found that other wild herbivores such as deer preferred to debark very small trees $(\mathrm{dbh}<5 \mathrm{~cm})$, at least for other species not belonging to Rosaceae family (Akashi and Nakashizuka, 1999; Iijima and Nagaike, 2015; Vospernik, 2006). Klich (2017) also showed higher debarking damage on trees with dbh $5-11 \mathrm{~cm}$ as compared to those with $\mathrm{dbh}$ around $20 \mathrm{~cm}$. Our results suggest that domestic herbivores repeatedly debark fruit trees and therefore trees accumulate debarking damages over time. In addition, most of the previous research related to debarking and rubbing have focused on wild herbivores, mainly deer -Cervidae- and caprins -Caprinae-in forests and woodlands (Gill, 1992; Kiffner et al., 2008; Perea et al., 2015; Velamazán et al., 2018). Some of these studies do not discriminate between rubbing and debarking damage. In our case, we only documented debarking damage because rubbing damage by domestic herbivores is null for horses and sheep (no horns). For cattle, rubbing damage is rare as compared to deer given that cows have either no apparent horns or permanent horns instead of the branched deer antlers that are shed annually (Goss, 1969) and required fraying or rubbing (Geist, 1998; Ramos et al., 2006).

Interestingly, tree density showed lower importance on debarking occurrence and intensity as compared to tree size and grazer species. As expected, lower tree densities significantly increased the probability of debarking occurrence but this mostly happened for low and medium levels of debarking intensity ( $<25 \%$ trunk damage), probably as a result of repeated tree damage on older and larger trees.

\subsection{Debarking impact on crown health and development}

Interestingly, crown health and development was strongly affected by debarking intensity. Trees with heavy and maximum debarking damage showed $>90 \%$ probability of crown damage. This damage level could be used as sustainability threshold, given that trunk damage $>50 \%$ is typically associated with crown damage (Fig. 3). Debarking is known to limit the normal functioning of the vascular system, which will in turn affect the adequate crown development. Furthermore, debarked trees represent suitable conditions for fungi development, and it induces a tree decay (Vasiliauskas, 1998). For example, for European oak (Quercus robur L.), which has a bark relatively rich in vitamins, minerals and water, more than $50 \%$ of developed stems decay after trunk debarking (Vasiliauskas, 1998).

Hence, it is important to avoid high levels of debarking in order to mantain healthy and well developed crowns which may provide higher fruit production (Charco et al., 2016), and mantain the general plant development and timber quality (Gill, 1992; Nielsen et al., 1982); in other words conserve the general stand stability. Once a tree is debarked, the probability of future damages on the same tree is usually higher, at least for wild ungulates (Gill, 1992; Staines and Welch, 1984). One reason might be that it is easier to debark (less effort for animals) once the bark is opened (first layers are harder); but also, animals might have a permanent habit to debark the same trees (Staines and Welch, 1984). Therefore, further studies should focus on livestock behaviour since it might represent a useful tool to better protect the trees.

\subsection{Implications for conservation management of traditional orchards}

Fruit trees need adequate management practices for their conservation and development, but also for the general sustainability of the overall traditional orchards which include many other biodiversity components and facets (e.g., European protected grasslands, tree genetics, valuable habitats for target bird species) as well as economically sustainable systems (Seehofer et al., 2014). To preserve orchard trees we recommend using individual tree-protection in farms with livestock, especially those with horse and cattle rearing. Here, we found that tree-protection was an efficient tool against all grazer species in the short-term. No long-term research has been conducted, but the use of protectors may avoid the long damage legacy in many traditional orchards, particularly in large herbivore-grazed areas. Therefore, if possible, the agricultural subsidies of the European Union should promote individual tree-protection in order to maintain different grazer species such as cattle and horse and reduce possible economic losses derived from the reduction of more highly-commercially livestock regimes such as cattle (López-Sánchez, 2015). Sheep had low impact on fruit trees in line with Geddes and Kohl (2009), and might represent an important complement of grazing diversity, especially in traditional orchards without individual tree-protection. The idea of permanent exclusion of livestock from orchards is not recommendable since their grazing activity provides several benefits to the system such as higher species richness in grasslands (López-Sánchez et al., 2016; Sternberg 
et al., 2000), reduction in competition of annual grasses (Gordon et al., 1989), and cultural maintenance (González-Rebollar and Ruiz-Mirazo, 2014). However, further research should evaluate the effect of different stocking rates on tree damage during similar periods and for each livestock management regime in order to estimate sustainable densities. In addition, the use of multi-specific management regimes with two or more livestock species should be also explored as it has been proposed for other rangelands and wood pastures (López-Sánchez, 2015; Perea et al., 2016).

Higher tree densities may indeed reduce overall tree damage by livestock and revitalize the damaged tree layer through new replanted individuals. However, further studies should address the profitability of having greater number of trees of lower size and quality. In addition, greater tree density may reduce animal mobility and pasture production, eventually reducing livestock profitability.

Finally, agriculture subsides (e.g. those coming from the Common Agriculture Policy - CAP- of European Union) per quality of fruit yield or per established protector might boost land owners to establish adequate tree conservation measures. Nowadays, traditional orchards are no longer profitable from a purely economic viewpoint (Plieninger et al., 2015b). However, their ecological cultural landscape values are so precious. Ecological indicators of sustainability such as tree debarking damage are therefore necessary to establish and promote sustainable management regimes. Therefore, efforts on knowledge transfer are required to embrace sensitivity and passion of those who manage these traditional and highly valuable systems to ensure their conservation and long-term sustainability.

\section{Conclusions}

Worldwide scattered trees are keystones in many human-modified landscapes and provide a wide variety of ecosystem services and functions (Garbarino and Bergmeier, 2014; López-Sánchez, 2015; Manning et al., 2006). In traditional grazed orchards, tree debarking is a common phenomenon. Cattle- and horse-grazed orchards held stronger debarking damage on their trees than sheep-grazed orchards. These unsustainable levels of cumulative debarking caused a decay of crown development, which may strongly affect fruit production. Individual tree-protection was an effective practice in decreasing trunk debarking. The impact of grazing animals on trees might represent a useful indicator to assess the sustainability of each grazing system and should be taken into account in future agriculture and conservation policies.

\section{Funding}

The study was financed by the following PhD fellowships: Spanish Ministry of Education, Culture and Sport, and Consejo Social of Universidad Politécnica de Madrid to A. López-Sánchez; and German Federal Environmental Foundation (DBU) (AZ 20012/175) to A. Schmitz.

\section{Acknowledgments}

We would like to thank all participating landowners as well as Biostation Oberberg and Biostation Rhein-Sieg for their collaboration and accessibility to different farms.

\section{Appendix A. Supplementary data}

Supplementary data to this article can be found online at https://doi. org/10.1016/j.jenvman.2019.110010.

\section{References}

Akashi, N., Nakashizuka, T., 1999. Effects of bark-stripping by Sika deer (Cervus nippon) on population dynamics of a mixed forest in Japan. For. Ecol. Manag. 113, 75-82. Bartolome, J.W., McClaran, M.P., 1992. Composition and production of California oak savanna seasonally grazed by sheep. J. Range Manag. 103-107.
Barton, K., 2015. MuMIn: multi-model inference. R packag, version 1.15.1. https:// CRAN.R-project.org/package $=$ MuMIn.

Bates, D., Maechler, M., Bolker, B., Walker, S., 2015. Fitting linear mixed-effects models using lme4. J. Stat. Softw. $67,1-48$.

Burnham, K.P., Anderson, D.R., 2002. Model Selection and Multi-Model Inference: a Practical Information-Theoretic Approach, second ed. edn. Springer Verlag, New York, USA.

Charco, J., Perea, R., Gil, L., Nanos, N., 2016. Impact of deer rubbing on pine forests: implications for conservation and management of Pinus pinaster populations. Eur. J. For. Res. 135, 719-729.

Cornelissen, P., Gresnigt, M.C., Vermeulen, R.A., Bokdam, J., Smit, R., 2014. Transition of a Sambucus nigra L. dominated woody vegetation into grassland by a multispecies herbivore assemblage. J. Nat. Conserv. 22, 84-92.

Crawley, M.J., 2012. The R Book. John Wiley \& Sons.

Dale, V.H., Beyeler, S.C., 2001. Challenges in the development and use of ecological indicators. Ecol. Indicat. 1, 3-10.

Eichhorn, M., Paris, P., Herzog, F., Incoll, L., Liagre, F., Mantzanas, K., Mayus, M., Moreno, G., Papanastasis, V., Pilbeam, D., 2006. Silvoarable systems in Europe-past, present and future prospects. Agrofor. Syst. 67, 29-50.

ESTO PROJECT, 2014. European Specialist in Traditional Orchards (accessed 17 June 2018). www.esto-project.eu.

Fischer, J., Stott, J., Law, B.S., 2010. The disproportionate value of scattered trees. Biol. Conserv. 143, 1564-1567.

Fox, J., Weisberg, S., 2011. An $\{$ R $\}$ Companion to Applied Regression. Sage, Thousand Oaks CA.

Garbarino, M., Bergmeier, E., 2014. 7 Plant and vegetation diversity in European woodpastures. In: Hartel, T., Plieninger, T. (Eds.), European Wood-pastures in Transition: A Social-Ecological Approach. Routledge, pp. 113-131.

Geddes, P., Kohl, R., 2009. Shropshire Sheep Control Weeds in Orchards. Pestic. News 3-4.

Geist, V., 1998. Deer of the World: Their Evolution, Behaviour, and Ecology. Stackpole books.

Gibbons, P., Lindenmayer, D.B., Fischer, J., Manning, A.D., Weinberg, A., Seddon, J., Ryan, P., Barrett, G., 2008. The future of scattered trees in agricultural landscapes. Conserv. Biol. 22, 1309-1319.

Gill, R.M.A., 1992. A review of damage by mammals in north temperate forests: 1. Deer. Forestry: Int. J. Financ. Res. 65, 145-169.

González-Rebollar, J.L., Ruiz-Mirazo, J., 2014. El papel del ganado doméstico en la naturalización del monte mediterráneo. Pastos 43, 7-12.

Gordon, D.R., Menke, J.M., Rice, K.J., 1989. Competition for soil water between annual plants and blue oak (Quercus douglasii) seedlings. Oecologia 79, 533-541.

Goss, R.J., 1969. Photoperiodic control of antler cycles in deer. I. Phase shift and frequency changes. J. Exp. Zool. 170, 311-324.

Herzog, F., 1998. Streuobst: a traditional agroforestry system as a model for agroforestry development in temperate Europe. Agrofor. Syst. 42, 61-80.

Horak, J., Peltanova, A., Podavkova, A., Safarova, L., Bogusch, P., Romportl, D., Zasadil, P., 2013. Biodiversity responses to land use in traditional fruit orchards of a rural agricultural landscape. Agric. Ecosyst. Environ. 178, 71-77.

Hünig, C., Benzler, A., 2017. In: Das Monitoring der Landwirtschaftsflächen mit hohem Naturwert. Deutschland, Bonn.

Ihwagi, F.W., Vollrath, F., Chira, R.M., Douglas-Hamilton, I., Kironchi, G., 2010. The impact of elephants, Loxodonta africana, on woody vegetation through selective debarking in Samburu and Buffalo Springs National Reserves, Kenya. Afr. J. Ecol. 48, 87-95.

Iijima, H., Nagaike, T., 2015. Appropriate vegetation indices for measuring the impacts of deer on forest ecosystems. Ecol. Indicat. 48, 457-463.

Jordan, J.A., 2011. Apples, identity, and memory in post-1989 Germany. In: Fuchs, A., Kathleen, J., Linda, S. (Eds.), Debating German Cultural Identity since 1989. Camden House, Rochester, New York, USA, pp. 46-66.

Kiffner, C., Rossiger, E., Trisl, O., Schulz, R., Rühe, F., 2008. Probability of recent bark stripping damage by red deer (Cervus elaphus) on Norway spruce (Picea abies) in a low mountain range in Germany-a preliminary analysis. Silva Fenn. 42, 125.

Kinnaird, J.W., Welch, D., Cummins, C., 1979. Selective stripping of rowan (Sorbus aucuparia L.) bark by cattle in North-East Scotland. Transactions of the Botanical Society of. Taylor \& Francis, Edinburgh, pp. 115-125.

Klich, D., 2017. Selective bark stripping of various tree species by Polish horses in relation to bark detachability. For. Ecol. Manag. 384, 65-71.

Kuiters, A.T., Van der Sluijs, L.A.M., Wytema, G.A., 2006. Selective bark-stripping of beech, Fagus sylvatica, by free-ranging horses. For. Ecol. Manag. 222, 1-8.

Leigh, J., 1974. Diet selection and the effects of grazing on the composition and structure of arid and semi-arid vegetation. Stud. Aust. Arid Zone 2, 102-126.

Loiseau, P., Martin-Rosset, W., Merle, G., 1989. Evolution à long terme d'une lande de montagne pâturée par des bovins ou des chevaux. II. Production fourragère. Agronomie 9, 161-169.

López-Sánchez, A., 2015. Balancing Management and Preservation of Mediterranean Scattered Oak Woodlands (Dehesas) in Human-Dominated Landscapes. Universidad Politécnica de Madrid, Spain).

López-Sánchez, A., Miguel, A.S., Dirzo, R., Roig, S., 2016. Scattered trees and livestock grazing as keystones organisms for sustainable use and conservation of Mediterranean dehesas. J. Nat. Conserv. 33, 58-67. https://doi.org/10.1016/j. jnc.2016.07.003.

Lucke, R., Silbereisen, R., Herzberger, E., 1992. Obstbäume in der Landschaft. Ulmer, Stuttgart, Germany.

Ludwig, F., de Kroon, H., Berendse, F., Prins, H.H.T., 2004. The influence of savanna trees on nutrient, water and light availability and the understorey vegetation. Plant Ecol. 170, 93-105. 
Luick, R., Vonhoff, W., 2009. Wertholzpflanzungen-das thema agroforstsysteme in moderner inszenierung. Naturschutz Landschaftsplan. 41, 47-52.

Manning, A.D., Fischer, J., Lindenmayer, D.B., 2006. Scattered trees are keystone structures-implications for conservation. Biol. Conserv. 132, 311-321.

Menke, N., Homeyer, M., 2009. Streuobstwiesenschutz in Nordrhein-Westfalen: erhalt des Lebensraumes, Anlage, Pflege, Produktvermarktung. In: Ministerium für Umwelt- und Naturschutz, Landwirtschaft und Verbraucherschutz des Landes Nordrhein-Westfalen: Referate Ökolandbau und Naturschutz.

Moreno, G., Franca, A., Pinto-Correia, T., Godinho, S., 2014. Multifunctionality and dynamics of silvopastoral systems. Options Méditerranéennes, Ser. A 109, 421-436.

Mountford, E.P., Peterken, G.F., 2003. Long-term change and implications for the management of wood-pastures: experience over 40 years from Denny Wood. New For. For. 76, 19-43.

Nerlich, K., Graeff-Hönninger, S., Claupein, W., 2013. Agroforestry in Europe: a Review of the Disappearance of Traditional Systems and Development of Modern Agroforestry Practices, with Emphasis on Experiences in Germany. Springer.

Nicodemo, M.L.F., Porfírio-da-Silva, V., 2018. Bark stripping by cattle in silvopastoral systems. Agrofor. Syst. 1-11.

Nielsen, D.G., Dunlap, M.J., Miller, K.V., 1982. Pre-rut rubbing by white-tailed bucks: nursery damage, social role, and management options. Wildl. Soc. Bull. 341-348.

Pantera, A., Burgess, P.J., Losada, R.M., Moreno, G., López-Díaz, M., Corroyer, N., McAdam, J., Rosati, A., Papadopoulos, A., Graves, A., 2018. Agroforestry for high value tree systems in Europe. Agrofor. Syst. 92, 945-959.

Perea, R., López-Sánchez, A., Roig, S., 2016. The use of shrub cover to preserve Mediterranean oak dehesas: a comparison between sheep, cattle and wild ungulate management. Appl. Veg. Sci. 19, 244-253.

Perea, R., Perea-García-Calvo, R., Díaz-Ambrona, C.G., San Miguel, A., 2015. The reintroduction of a flagship ungulate Capra pyrenaica: assessing sustainability by surveying woody vegetation. Biol. Conserv. 181, 9-17.

Plieninger, T., 2012. Monitoring directions and rates of change in trees outside forests through multitemporal analysis of map sequences. Appl. Geogr. 32, 566-576.

Plieninger, T., Hartel, T., Martín-López, B., Beaufoy, G., Bergmeier, E., Kirby, K., Montero, M.J., Moreno, G., Oteros-Rozas, E., Van Uytvanck, J., 2015. Wood-pastures of Europe: geographic coverage, social-ecological values, conservation management, and policy implications. Biol. Conserv. 190, 70-79.

Plieninger, T., Levers, C., Mantel, M., Costa, A., Schaich, H., Kuemmerle, T., 2015. Patterns and drivers of scattered tree loss in agricultural landscapes: orchard meadows in Germany (1968-2009). PLoS One 10, e0126178.

R Development Core Team, 2015. R: a Language and Environment for Statistical Computing. Foundation for Statistical Computing, Vienna, Austria.

Ramos, J.A., Bugalho, M.N., Cortez, P., Iason, G.R., 2006. Selection of trees for rubbing by red and roe deer in forest plantations. For. Ecol. Manag. 222, 39-45.
Rivas-Martínez, S., Fernández-González, F., Loidi, J., Lousã, M., Penas, A., 2001. Syntaxonomical Checklist of Vascular Plant Communities of Spain and Portugal to Association Level. Itinera geobotanica.

Robertson, H., Wedge, C., 2008. Traditional orchards and the UK biodiversity action plan. An introduction to orchards and groves: their history, ecology, culture and archaeology. Lanscape Archaeol. Ecol. 7, 109-118.

Rolo, V., Rivest, D., López-Díaz, M.L., Moreno, G., 2015. Microhabitat effects on herbaceous nutrient concentrations at the community and species level in Mediterranean open woodlands: the role of species composition. Grass Forage Sci. 70, 219-228.

Rook, A., Dumont, B., Isselstein, J., Osoro, K., WallisDeVries, M., Parente, G., Mills, J., 2004. Matching type of livestock to desired biodiversity outcomes in pastures-a review. Biol. Conserv. 119, 137-150.

Seehofer, H., Wagner, F., Mayer, M., Baumhof-Pregitzer, M., Geiger, J., Habeck, J., Heinzelmann, R., Küpfer, C., Meyer, M., 2014. Vogelschutz in Streuobstwiesen des Mittleren Albvorlandes und des Mittleren Remstales. Regierungspräsidium Stuttgart, Ref. 56 (Naturschutz und Landschaftspflege).

Staines, B.W., Welch, D., 1984. Habitat selection and impact of red (Cervus elaphus L.) and roe (Capreolus capreolus L.) deer in a Sitka spruce plantation. Proc. Roy. Soc. Edinb. Sect. B Biol. Sci. 82, 303-319.

Sternberg, M., Gutman, M., Perevolotsky, A., Ungar, E.D., Kigel, J., 2000. Vegetation response to grazing management in a Mediterranean herbaceous community: a functional group approach. J. Appl. Ecol. 37, 224-237.

Vasiliauskas, R., 1998. Patterns of wounding and decay in stems of Quercus robur due to bark peeling. Scand. J. For. Res. 13, 437-441.

Velamazán, M., San Miguel, A., Escribano, R., Perea, R., 2017. Threatened woody flora as an ecological indicator of large herbivore introductions. Biodivers. Conserv. 26, 917-930.

Velamazán, M., San Miguel, A., Escribano, R., Perea, R., 2018. Compatibility of regeneration silviculture and wild ungulates in a Mediterranean pine forest: implications for tree recruitment and woody plant diversity. Ann. For. Sci. 75, 35.

Venables, W.N., Ripley, B.D., 2002. Modern Applied Statistics with S. Springer.

Vospernik, S., 2006. Probability of bark stripping damage by red deer (Cervus elaphus) in Austria. Silva Fenn. 40, 589.

Walker, J.W., 1994. Multispecies grazing: the ecological advantage. Sheep Res. J. 52-64. Weller, F., 2006. XI. Streuobstwiesen. In: Konold, W., Böcker, R., Hampicke, U. (Eds.), Handbuch Naturschutz und Landschaftspflege. Wiley-VCH, Weinheim, pp. 1-42.

Zuur, A.F., Ieno, E.N., Walker, N.J., Saveliev, A.A., Smith, G.M., 2009. Mixed effects modelling for nested data. Mixed Effects Models and Extensions in Ecology with R. Springer, pp. 101-142. 